\title{
Preference Mapping of Cheddar Cheese with Varying Maturity Levels
}

\author{
N. D. Young, ${ }^{1}$ M. Drake, ${ }^{1}$ K. Lopetcharat ${ }^{2}$ and M. R. McDaniel ${ }^{2}$ \\ ${ }^{1}$ Department of Food Science, Southeast Dairy Foods Research Center, \\ North Carolina State University, Raleigh 27694-7624 \\ ${ }^{2}$ Department of Food Science, Oregon State University, Sensory Science Laboratory, \\ Oregon State University, 100 Wiegand Hall, Corvallis 97331-6602
}

\begin{abstract}
The objective of this study was to evaluate the flavor profile and acceptability of 7 Cheddar cheeses of varying maturity using descriptive analysis and consumer acceptance tests. Cheddar cheeses $(n=7)$ ranging in age from 1 to 19 mo were selected based on age, geographic region, and flavor profile. Descriptive sensory profiles of selected cheeses were determined using a trained panel $(n=14)$ and an established cheese flavor sensory language. Cheeses were evaluated for consumer acceptability in two demographic locations: North Carolina and Oregon. Consumers ( $\mathrm{n}=100$ at each location) assessed the cheeses for overall liking and other consumer attributes. Cheddar cheeses demonstrated distinct differences in descriptive sensory profiles. Average consumer responses between the two locations were not different. Six distinct consumer clusters were identified, and the number of consumers in these clusters differed between the two locations. Consumers differentiated "young" and "aged" cheese flavor, but both young and mature cheeses were perceived by consumers as exhibiting intense Cheddar cheese flavors. Cheddar cheese acceptance varies widely among consumers and is related to consumer preferences for distinct cheese flavor profiles.
\end{abstract}

(Key words: cheese flavor, sensory analysis, descriptive analysis, preference mapping)

Abbreviation key: GPA = generalized procrustes analysis, NCSU = North Carolina State University, OSU = Oregon State University, PCA = principal component analysis.

\section{INTRODUCTION}

Flavor is widely recognized as a significant factor of cheese acceptance and quality. Extensive research has been conducted in understanding Cheddar cheese flavor

Received April 14, 2003.

Accepted June 6, 2003.

Corresponding author: M. A. Drake; e-mail: mdrake@unity. ncsu.edu . through analytical and sensory analysis methods. Sensory methods have been used to determine Cheddar cheese flavor attributes using descriptive analysis and consumer evaluation methods (McEwan et al., 1989; Muir et al., 1997; Fenelon et al., 2000; Guldfeldt et al., 2001). In 2001, Drake et al. published a Cheddar cheese flavor lexicon for describing Cheddar cheese flavor attributes. The language was subsequently validated using independently trained sensory panels at three sites (Drake et al., 2002). The development of a standardized flavor lexicon for Cheddar flavor provides a platform to link perceived flavors to volatile components and to consumer perception (Drake and Civille, 2003).

Preference mapping assists scientists in understanding the descriptive sensory attributes that influence consumer preferences (Schlich, 1995; McEwan, 1996; Murray and Delahunty, 2000). Preference mapping techniques are commonly used to examine the relationship between descriptive sensory data and consumer responses (McEwan, 1996). The two main areas of preference mapping are internal preference mapping and external preference mapping. Internal preference mapping is a principal component analysis (PCA) of the matrix of hedonic scores across the products (the observations) and the consumer (the variables), which is carried out on a covariance matrix to allow for differences in the strength of the consumer preferences to be expressed (Guinard, 1998). External preference mapping regresses individual consumer preferences onto the first two principal components of the covariance matrix of descriptive or other analytical ratings across products (Schlich, 1995; Guinard, 1998). In external preference mapping, the dimensions of the descriptive analysis space are the predictor variables, whereas consumer acceptability is the response variable (Schlich, 1995). Both internal and external preference mapping techniques have been implemented in an increasing number of dairy research studies (Pagliarini et al., 1997; Hough and Sánchez, 1998; Yackinous et al., 1999; Murray and Delahunty, 2000; Richardson-Harman et al., 2000).

Limited research has been performed using preference mapping techniques to understand consumer perception and acceptability of the flavor profiles of Cheddar cheese. Cheddar cheese flavor is characterized by 
Table 1. Production and age description of Cheddar cheeses selected for this study.

\begin{tabular}{llc}
\hline Cheese & Location of manufacture & $\begin{array}{c}\text { Age } \\
\text { (mo) }\end{array}$ \\
\hline Treatment 1 & Midwest, stirred curd, location 1 & 1 \\
Treatment 2 & Midwest, milled curd, location 2 & 4 \\
Treatment 3 & Midwest, milled curd, location 2 & 8 \\
Treatment 4 & Midwest, milled curd, location 3 & 12 \\
Treatment 5 & Midwest, milled curd, location 3 & 19 \\
Treatment 6 & Northeast, milled curd, location 4 & 19 \\
Treatment 7 & Northeast, milled curd, location 5 & 19 \\
\hline
\end{tabular}

complex flavors associated with age and processing procedures; cheeses with varying maturity levels have distinctive flavor profiles (Drake et al., 2001). Moreover, diverse demographics might have different attitudes relating to the consumer acceptability of Cheddar cheese. The objective of this study was to evaluate the flavor profile and acceptability of 7 Cheddar cheeses of varying maturity using descriptive analysis and consumer acceptance tests.

\section{MATERIALS AND METHODS}

\section{Selection of Cheeses}

Cheddar cheeses $(n=7)$ ranging in age from 1 to 19 mo were selected based on age and flavor profile from a diverse set $(\mathrm{n}=30)$ of commercial $20-\mathrm{kg}$ Cheddar cheese blocks received at North Carolina State University (NCSU). The cheeses were screened and the 7 blocks selected for the study by flavor evaluation by 4 individuals each with more than $200 \mathrm{~h}$ of experience with sensory analysis of Cheddar cheese flavor. Cheeses were stored at $7^{\circ} \mathrm{C}$ in the dark until analysis. All cheeses were full fat commercial US Cheddar cheeses, made from pasteurized milk with less than 39\% moisture (wt/ wt) (Table 1).

\section{Descriptive Sensory Analysis}

Sensory testing was conducted in compliance with NCSU Institutional Review Board for Human Subjects approval. Cheddar cheeses were cut into 1 -inch cubes for descriptive sensory analysis. The cheeses were placed into 4-oz. soufflé cups with 3 -digit codes. The cheeses were tempered at $10^{\circ} \mathrm{C}$ for $1 \mathrm{~h}$ and were served at this temperature with spring water and unsalted crackers for palate cleansing. Descriptive analysis was conducted at NCSU and used a 15-point universal intensity scale with the Spectrum ${ }^{\mathrm{TM}}$ method (Meilgaard et al., 1999; Drake and Civille, 2003) and a cheese flavor sensory language (Drake et al., 2001) (Table 2). A trained descriptive sensory panel $(\mathrm{n}=14)$ with over 150 $h$ of experience each with descriptive analysis of cheese flavor evaluated the cheeses. Consistent with Spectrum $^{\mathrm{TM}}$ descriptive analysis training, panelists were presented with reference solutions of sweet, sour, salty, and bitter tastes to learn to consistently use the universal intensity scale (Meilgaard et al., 1999; Drake and Civille, 2003). Following consistent use of the Spectrum $^{\mathrm{TM}}$ scale with basic tastes, panelists learned to identify and scale flavor descriptors using the same intensity scale through presentation and discussion of flavor definitions, references (Table 2) and a wide array of cheeses. Discussion and evaluation of a wide array of cheeses (Cheddar and other cheeses) was also conducted during training to enable panelists to consistently differentiate and replicate samples. Analysis of data collected from training sessions confirmed that panel results were consistent and that terms were not redundant, consistent with previous use of the developed language (Drake et al., 2001). Cheeses were evaluated monadically in triplicate in a randomized balanced block design. Evaluations were conducted individually in an enclosed room dedicated to sensory analysis and free from external aromas, noise, and distractions. Panelists were instructed to expectorate samples after evaluation. Spring water was available to each panelist for palate cleansing.

\section{Consumer Evaluation}

Consumer evaluation was conducted within 2 wk of the descriptive analysis of the cheeses. Cheeses were evaluated in two demographic locations: North Carolina and Oregon. Cheeses were sliced into 5 -kg blocks, vacuum-sealed, and mailed by overnight carrier on ice gel packs to Oregon State University (OSU). Consumer testing was conducted at the OSU Sensory Center and at the NCSU Sensory Center in sensory booths. Testing at both sites was coordinated and conducted simultaneously. At OSU, consumers were recruited by e-mail from a database of over 1000 members of the Corvallis, OR, community. At NCSU, consumers were recruited from the university students, staff, and faculty through emails and fliers.

Testing procedure was identical at each site. The Cheddar cheeses $(n=7)$ were tested across $2 d$ at each site using a constant control cheese presented each day. A constant control cheese was presented along with 3 cheeses each day (4 cheeses evaluated each day) to reduce the sample testing bias that could be associated with testing across $2 \mathrm{~d}$. The constant control cheese that was presented both days was selected from descriptive analysis results based on its moderate flavor intensities. Cheeses were cut into 1 -inch cubes and dispensed into 4-oz. soufflé cups with lids numbered with 3-digit codes. The cheeses were served at $10^{\circ} \mathrm{C}$. Consumers 
Table 2. Sensory language used for descriptive analysis of Cheddar cheeses. ${ }^{1}$

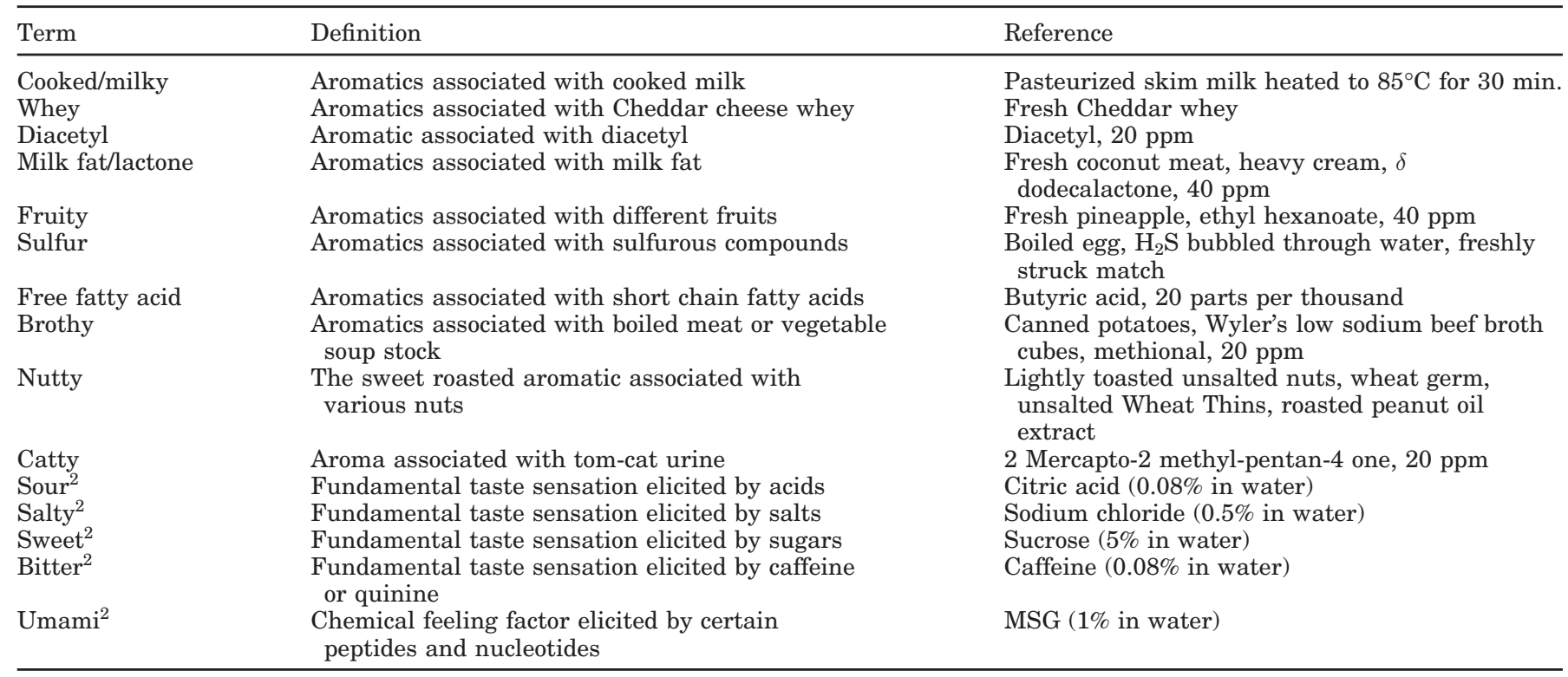

${ }^{1}$ Taken from Drake et al., 2001.

${ }^{2}$ Reference taken from Meilgaard at al., 1999.

( $\mathrm{n}=100$ at each location) were provided with consent forms consistent with NCSU Human Subjects approval, screener forms, and a scoring ballot. Cheeses were presented individually in a randomized balanced order (following presentation of the constant control cheese). A screener form was designed for collecting demographic information and evaluating consumer decisions for cheese and/or cheese products. The ballot was used to evaluate consumer evaluations of cheese for: overall acceptance, overall color liking, overall flavor liking, overall texture liking, and the intensity of overall Cheddar cheese flavor and overall aged cheese flavor using a 9-point hedonic scale where 1 = dislike extremely or low intensity and $9=$ like extremely or high intensity. Consumers were provided with spring water and unsalted crackers for palate cleansing. Consumers were provided with gift certificates (Oregon) or food treats (North Carolina) for their participation.

\section{Statistical Analysis}

Univariate and multivariate statistical methods were used in analyzing the results. Descriptive and consumer data were analyzed individually and then together. Analysis of variance with means separation and PCA was used to analyze the descriptive data (SAS, version 8.2, Cary, NC). Chi-squared tests (PROC FREQ) were conducted to compare consumer demographic data from each location (SAS, version 8.2, Cary, NC). Frequency histograms of consumer results were created and investigated for each attribute to determine whether bimodal distributions occurred. Analysis of variance with means separation was then conducted. Correlation analysis was conducted on descriptive and consumer data individually and together to determine linear relationships. Possible nonlinear relationships between consumer attributes and cheese attribute intensities were visually assessed using scatterplots.

Internal preference mapping was conducted on consumer means using SAS (version 8.2, Cary, NC) (PROC PRINQUAL) and treatment mean scores were plotted on the resulting principal component eigenvectors. External preference mapping was conducted on the descriptive data and the consumer acceptance scores using SPSS (v 10, Chicago, IL) and Sensetools (OP\&P Product Research, Utrecht, The Netherlands). Briefly, consumer acceptability scores were segmented using PCA followed by cluster analysis. Clusters were confirmed using discriminant analysis. Generalized procrustes analysis (GPA) was then used to relate consumer clusters and descriptive data. Characteristics of each cluster were determined by analysis of variance of acceptance scores within each cluster and examining the external preference map.

\section{RESULTS AND DISCUSSION}

\section{Descriptive Analysis}

Descriptive analysis results showed distinguishing flavor differences between the Cheddar cheeses (Table 3) (Figure 1). The Spectrum ${ }^{\mathrm{TM}}$ descriptive analysis tech- 
YOUNG ET AL.

Table 3. Descriptive attribute means $(n=14)$ for the Cheddar cheeses. ${ }^{1}$

\begin{tabular}{llllllll}
\hline Cheese & Trt 1 & Trt 2 & Trt 3 & Trt 4 & Trt 5 & Trt 6 & Trt 7 \\
\hline Cooked & $2.7^{\mathrm{a}}$ & $2.5^{\mathrm{a}}$ & $2.5^{\mathrm{a}}$ & $1.2^{\mathrm{b}}$ & $0.8^{\mathrm{d}}$ & $0.8^{\mathrm{bd}}$ & $0.6^{\mathrm{d}}$ \\
Whey & $2.9^{\mathrm{a}}$ & $3.0^{\mathrm{a}}$ & $3.0^{\mathrm{a}}$ & $0.6^{\mathrm{b}}$ & $0.2^{\mathrm{d}}$ & $0.2^{\mathrm{d}}$ & $0.2^{\mathrm{d}}$ \\
Diacetyl & $2.4^{\mathrm{a}}$ & $1.5^{\mathrm{b}}$ & $1.5^{\mathrm{b}}$ & $0.4^{\mathrm{d}}$ & $0.2^{\mathrm{d}}$ & $0.1^{\mathrm{d}}$ & $0.0^{\mathrm{d}}$ \\
Milkfat/lactone & $2.8^{\mathrm{a}}$ & $2.4^{\mathrm{ab}}$ & $2.1^{\mathrm{b}}$ & $0.8^{\mathrm{d}}$ & $0.5^{\mathrm{d}}$ & $0.7^{\mathrm{d}}$ & $0.4 \mathrm{~d}$ \\
Fruity & $0.0^{\mathrm{d}}$ & $0.0^{\mathrm{d}}$ & $0.0^{\mathrm{d}}$ & $0.4^{\mathrm{a}}$ & $0.3^{\mathrm{b}}$ & $0.4^{\mathrm{a}}$ & $0.2^{\mathrm{d}}$ \\
Sulfur & $0.1 \mathrm{~d}$ & $0.4^{\mathrm{d}}$ & $0.5^{\mathrm{d}}$ & $3.1^{\mathrm{ab}}$ & $2.6^{\mathrm{b}}$ & $2.7^{\mathrm{b}}$ & $3.4^{\mathrm{a}}$ \\
Free fatty acid & $0.0^{\mathrm{d}}$ & $0.0^{\mathrm{d}}$ & $0.0^{\mathrm{d}}$ & $0.5^{\mathrm{a}}$ & $0.3^{\mathrm{b}}$ & $0.7^{\mathrm{a}}$ & $0.4^{\mathrm{b}}$ \\
Brothy & $0.2^{\mathrm{d}}$ & $0.5^{\mathrm{d}}$ & $0.7^{\mathrm{d}}$ & $2.6^{\mathrm{b}}$ & $4.0^{\mathrm{a}}$ & $2.4^{\mathrm{b}}$ & $2.7^{\mathrm{b}}$ \\
Nutty & $0.0 \mathrm{~d}$ & $0.2 \mathrm{~d}$ & $0.1 \mathrm{~d}$ & $1.5^{\mathrm{bd}}$ & $1.3^{\mathrm{d}}$ & $2.4^{\mathrm{a}}$ & $1.9^{\mathrm{b}}$ \\
Catty & $0.0^{\mathrm{d}}$ & $0.0^{\mathrm{d}}$ & $0.0^{\mathrm{d}}$ & $1.0^{\mathrm{a}}$ & $0.5^{\mathrm{b}}$ & $0.5^{\mathrm{b}}$ & $1.1^{\mathrm{a}}$ \\
Sweet & $1.7^{\mathrm{ab}}$ & $1.6^{\mathrm{b}}$ & $1.5^{\mathrm{b}}$ & $2.0^{\mathrm{a}}$ & $1.6^{\mathrm{b}}$ & $1.8^{\mathrm{a}}$ & $1.3^{\mathrm{b}}$ \\
Sour & $2.2^{\mathrm{d}}$ & $3.2^{\mathrm{ab}}$ & $3.3^{\mathrm{ab}}$ & $3.0^{\mathrm{b}}$ & $2.9^{\mathrm{b}}$ & $3.5^{\mathrm{a}}$ & $3.3^{\mathrm{ab}}$ \\
Salty & $2.7^{\mathrm{d}}$ & $2.9^{\mathrm{d}}$ & $3.1^{\mathrm{bd}}$ & $3.2^{\mathrm{bd}}$ & $3.1^{\mathrm{bd}}$ & $3.6^{\mathrm{a}}$ & $3.2^{\mathrm{b}}$ \\
Bitter & $0.1 \mathrm{~d}$ & $0.1 \mathrm{~d}$ & $0.2 \mathrm{~d}$ & $0.4^{\mathrm{d}}$ & $0.9^{\mathrm{b}}$ & $0.5^{\mathrm{d}}$ & $1.6^{\mathrm{a}}$ \\
Umami & $0.1^{\mathrm{b}}$ & $0.2^{\mathrm{b}}$ & $0.2^{\mathrm{b}}$ & $0.8^{\mathrm{a}}$ & $0.9^{\mathrm{a}}$ & $1.0^{\mathrm{a}}$ & $0.8^{\mathrm{a}}$ \\
\hline
\end{tabular}

a,b,c,d Means in a row followed by different letters represent significant differences $(P<0.05)$.

${ }^{1}$ Intensities scored on a 15 -point Universal Spectrum ${ }^{\mathrm{TM}}$ intensity scale where $0=$ none and 15 = very. For cheese descriptions, see Table 1.

nique utilizes a universal intensity scale for descriptor scaling (Meilgaard et al., 1999; Drake and Civille, 2003). By this method, panelists score intensities in the same manner across all attributes and all products. Because the scale is universal in nature, attribute intensities for many dairy products, including cheese, fall primarily between 0 and 7 , with most attributes between 0 and 4 (Drake et al., 2001, 2002). The advantages to this descriptive analysis technique are that one panel can be readily trained on multiple products because one intensity scale is used, different types of products can be directly compared, and panel scaling is less prone to drift with time (Drake and Civille, 2003).

Some Cheddar cheeses (treatments $1,2,3$ ) were characterized by the attributes "cooked/milky," "whey," "diacetyl," and "milkfat/lactone." These four attributes were

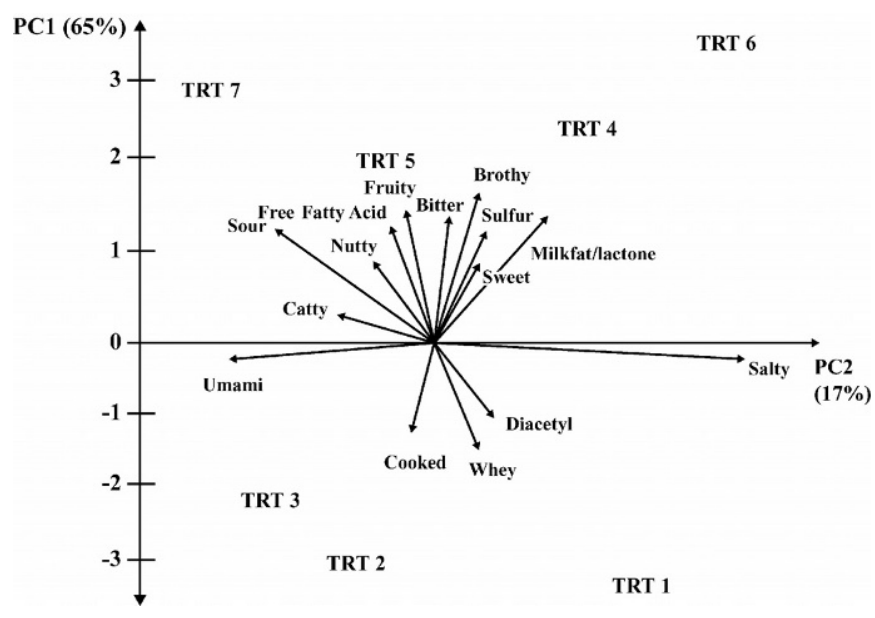

Figure 1. Principal component biplot of descriptive analysis of Cheddar cheeses. previously classified as "young/undeveloped" by Drake et al. (2001) due to their prevalence in Cheddar cheeses less than $1 \mathrm{yr}$ old. The cheeses in the present study that were characterized by these flavors were also less than $1 \mathrm{yr}$ old. The Cheddar cheeses that were older than $1 \mathrm{yr}$ were primarily characterized by the attributes "sulfur," "brothy," and "nutty" (treatments 4, 5, 6, 7) "Free fatty acid" and "catty" flavors were also detected in many of these more aged Cheddar cheeses. As previously reported (Drake et al., 2001), with increased cheese maturity, aged/developed flavors (sulfur, brothy, free fatty acid, nutty, and catty flavor attributes) become more prevalent as does the variety of Cheddar cheese flavors. Correlation analysis (Table 4) revealed positive correlations between the aged Cheddar cheese flavor attributes ("fruity," "free fatty acid," "sulfur," "brothy," and "nutty") and the basic tastes ("sour" and "salty" and "salty" and "umami"). The basic taste "umami" was also positively correlated with the aged flavor attributes ("fruity," "free fatty acid," "sulfur," "brothy," "nutty," and "catty") and negatively correlated with "cooked/milky," "whey," "diacetyl," and "milkfat/ lactone." Young Cheddar cheese flavor attributes ("cooked/milky," "whey," "diacetyl," and "milkfat/lactone") were negatively correlated with the mature Cheddar cheese flavor attributes. These relationships have been previously noted with Cheddar cheeses (Drake et al., 2001, 2003).

\section{Consumer Evaluation}

The consumer groups from the two locations differed in gender profile, segmentations by age, and types of cheese consumed $(P<0.05)$ (Table 5$)$. In contrast, cheese consumption habits and factors that influenced cheese choice/purchase were not different $(P>0.05)$. 
Table 4. Correlations between descriptive sensory attributes used to profile Cheddar cheeses. ${ }^{1}$

\begin{tabular}{|c|c|c|c|c|c|c|c|c|c|c|c|c|c|c|c|}
\hline Sample & Cooked & Whey & Diacetyl & Milk fat & Fruity & Sulfur & FFA & Brothy & Nutty & Catty & Sour & Bitter & Salty & Sweet & Umami \\
\hline Cooked & 1.00 & 0.99 & 0.97 & 0.99 & -0.89 & -0.99 & -0.87 & -0.94 & -0.93 & -0.91 & -0.40 & -0.75 & -0.68 & -0.05 & -0.97 \\
\hline Whey & & 1.00 & 0.94 & 0.97 & -0.91 & -0.98 & -0.90 & -0.93 & -0.94 & -0.89 & -0.34 & -0.71 & -0.69 & -0.14 & -0.98 \\
\hline Diacetyl & & & 1.00 & 0.98 & -0.85 & -0.95 & -0.84 & -0.91 & -0.91 & -0.84 & -0.60 & -0.70 & -0.76 & 0.02 & -0.96 \\
\hline Fruity & & & & & 1.00 & 0.88 & 0.94 & 0.83 & 0.89 & 0.73 & 0.33 & 0.36 & 0.76 & 0.49 & 0.94 \\
\hline Sulfur & & & & & & 1.00 & 0.87 & 0.90 & 0.92 & 0.95 & 0.42 & 0.73 & 0.67 & 0.04 & 0.94 \\
\hline \multicolumn{16}{|l|}{ Free } \\
\hline \multicolumn{16}{|l|}{ Fatty } \\
\hline Nutty & & & & & & & & & 1.00 & 0.81 & 0.52 & 0.63 & 0.86 & 0.17 & 0.95 \\
\hline Catty & & & & & & & & & & 1.00 & 0.31 & 0.76 & 0.49 & -0.10 & 0.80 \\
\hline Sour & & & & & & & & & & & 1.00 & 0.30 & 0.75 & -0.26 & 0.45 \\
\hline Bitter & & & & & & & & & & & & 1.00 & 0.32 & -0.56 & 0.62 \\
\hline Salty & & & & & & & & & & & & & 1.00 & 0.27 & 0.79 \\
\hline Sweet & & & & & & & & & & & & & & 1.00 & 0.21 \\
\hline Umami & & & & & & & & & & & & & & & 1.00 \\
\hline
\end{tabular}

${ }^{1}$ Numbers in bold represent significant correlations $(P<0.01)$.

Consumer acceptability responses for the cheeses between the two locations were not different by analysis of variance $(P>0.05)$. There were no differences in overall acceptance for the control cheese across the $2 \mathrm{~d}$ of testing for both locations $(P>0.05)$. Because consumer results across all attributes were consistent for the constant control cheese across the $2 \mathrm{~d}$ of testing for both locations $(P>0.05)$, consumer data across the $2 \mathrm{~d}$ were pooled. The consumer mean scores across both locations are featured in Table 6. Figures 2 and 3 are internal preference maps of the NCSU and OSU consumer data, respectively. The similarity between the two figures confirms the overall lack of differences noted between the two sites for the univariate analysis results.

The constant control cheese (treatment 3) received the highest consumer scores across all liking attributes $(P<0.05)$. This Cheddar cheese was initially chosen as

Table 5. Demographic information and consumption characteristics of cheese consumers.

\begin{tabular}{|c|c|c|}
\hline & $\begin{array}{l}\text { Location } 1(\mathrm{NCSU})^{1} \\
\mathrm{n}=101\end{array}$ & $\begin{array}{l}\text { Location } 2(\mathrm{OSU})^{2} \\
\mathrm{n}=110\end{array}$ \\
\hline $\begin{array}{l}\text { Gender* (\% males/females) } \\
\text { Age group* }\end{array}$ & $\begin{array}{l}43 / 57 \\
0 \% \leq 18 \text { y } \\
38 \% 19-25 \text { y } \\
30 \% 26-35 \text { y } \\
18 \% 36-45 \text { y } \\
10 \% 46-55 \text { y } \\
4 \%>56 \text { y }\end{array}$ & $\begin{array}{l}37 / 63 \\
1 \% \leq 18 \text { y } \\
20 \% 19-25 \text { y } \\
30 \% 26-35 \text { y } \\
18 \% 36-45 \text { y } \\
24 \% 46-55 \text { y } \\
7 \%>56 \text { y }\end{array}$ \\
\hline $\begin{array}{l}\text { Shop for household* } \\
\text { (\% yes/no) }\end{array}$ & $93 / 7$ & $100 / 0$ \\
\hline Cheese consumption & $\begin{array}{l}0 \% \text { never } \\
5 \% \text { once per mo } \\
18 \% 2-4 \text { times per mo } \\
77 \%>\text { once per wk }\end{array}$ & $\begin{array}{l}0 \% \text { never } \\
4 \% \text { once per mo } \\
15 \% 2-4 \text { times per mo } \\
81 \%>\text { once per wk }\end{array}$ \\
\hline Cheese types consumed ${ }^{* 3}$ & $\begin{array}{l}\text { 67\% Processed cheeses } \\
89 \% \text { Mild cheeses } \\
75 \% \text { Aged/strong flavored } \\
\text { cheeses }\end{array}$ & $\begin{array}{l}23 \% \text { Processed cheeses } \\
92 \% \text { Mild cheeses } \\
\text { 89\% Aged/strong flavored } \\
\text { cheeses }\end{array}$ \\
\hline Factors influencing choice of cheese & $\begin{array}{l}\text { 67\% Price } \\
97 \% \text { Flavor } \\
46 \% \text { Texture } \\
28 \% \text { Health } \\
40 \% \text { Availability }\end{array}$ & $\begin{array}{l}\text { 68\% Price } \\
99 \% \text { Flavor } \\
\text { 49\% Texture } \\
31 \% \text { Health } \\
38 \% \text { Availability }\end{array}$ \\
\hline
\end{tabular}


YOUNG ET AL.

Table 6. Combined NCSU ${ }^{1}$ and $\mathrm{OSU}^{2}$ consumer attribute means $(\mathrm{n}=211)$ for the Cheddar cheeses. (Consumer acceptability or perceived intensity scored on a 9 -point hedonic scale where $1=$ dislike extremely or low intensity and 9 = like extremely or high intensity.)

\begin{tabular}{llllllll}
\hline Cheese & Trt $1^{3}$ & Trt 2 & Trt 3 & Trt 4 & Trt 5 & Trt 6 & Trt 7 \\
\hline Overall acceptance & $5.7^{\text {cde }}$ & $7.2^{\mathrm{a}}$ & $6.5^{\mathrm{b}}$ & $5.6^{\mathrm{e}}$ & $6.1^{\mathrm{bcd}}$ & $5.7^{\mathrm{de}}$ & $6.3^{\mathrm{bc}}$ \\
Overall color liking & $6.4^{\mathrm{d}}$ & $7.5^{\mathrm{a}}$ & $6.6^{\mathrm{d}}$ & $6.7^{\mathrm{cd}}$ & $7.0^{\mathrm{bc}}$ & $7.1^{\mathrm{b}}$ & $7.1^{\mathrm{ab}}$ \\
$\begin{array}{l}\text { Overall flavor liking } \\
\text { Overall texture liking }\end{array}$ & $5.5^{\mathrm{cd}}$ & $7.2^{\mathrm{a}}$ & $6.0^{\mathrm{bc}}$ & $5.3^{\mathrm{d}}$ & $6.1^{\mathrm{b}}$ & $5.5^{\mathrm{d}}$ & $6.3^{\mathrm{b}}$ \\
$\begin{array}{l}\text { Overall cheddar } \\
\text { cheese intensity }\end{array}$ & $7.2^{\mathrm{a}}$ & $6.5^{\mathrm{bc}}$ & $6.3^{\mathrm{c}}$ & $6.5^{\mathrm{bc}}$ & $6.7^{\mathrm{b}}$ & $6.6^{\mathrm{bc}}$ \\
$\begin{array}{l}\text { Overall aged } \\
\text { cheese intensity }\end{array}$ & $4.1^{\mathrm{d}}$ & $7.0^{\mathrm{a}}$ & $6.3^{\mathrm{b}}$ & $6.3^{\mathrm{b}}$ & $5.5^{\mathrm{c}}$ & $6.2^{\mathrm{b}}$ & $6.9^{\mathrm{a}}$ \\
\hline
\end{tabular}

${ }^{\mathrm{a}, \mathrm{b}, \mathrm{c}, \mathrm{d}, \mathrm{e}}$ Means in a row followed by different letters represent significant differences $(P<0.05)$.

${ }^{1} \mathrm{NCSU}=$ North Carolina State University

${ }^{2} \mathrm{OSU}=$ Oregon State University.

${ }^{3}$ For cheese description, see Table 1.

the control in the consumer experimental design due to its primarily young/undeveloped or mild flavor profile. Treatments $4,5,6$, and 7 were characterized by descriptive analysis as exhibiting aged, mature cheese flavors, and these cheeses had the highest consumer scores for overall aged cheese intensity $(P<0.05)$. These results indicate that consumers can distinguish "young" and "aged" cheese flavors and that these concepts are consistent with descriptive sensory analysis. That is, young cheese flavors encompass cooked/milky, whey, diacetyl, and milkfat/lactone flavors, whereas aged cheese flavor comprises flavors including sulfur, brothy, nutty, fruity, and catty. Both young and mature cheeses were perceived by consumers as exhibiting intense Cheddar cheese flavors. Treatments 3 and 6 received the highest scores for Cheddar cheese flavor intensity. These cheeses were quite diverse in flavor character by de-

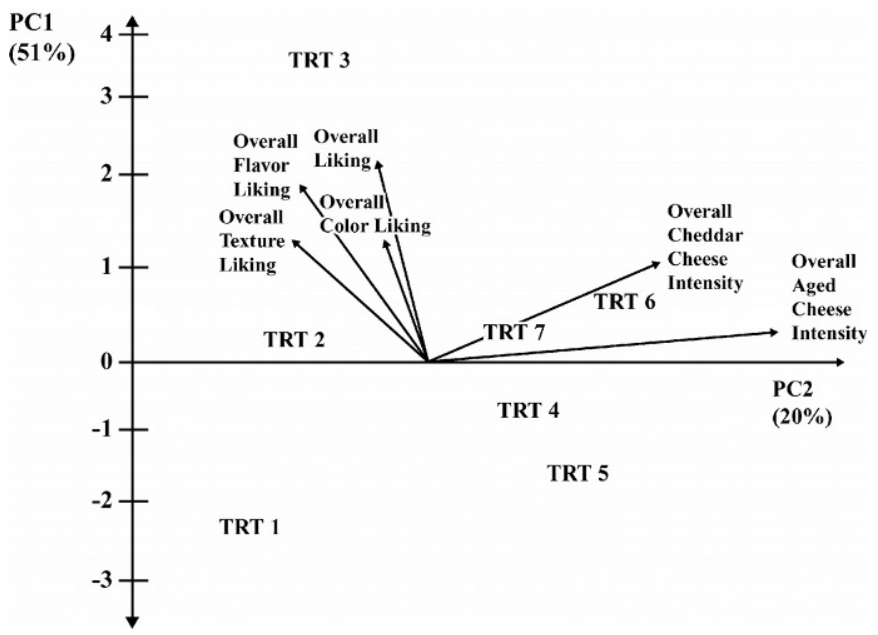

Figure 2. Internal preference map of perception of Cheddar cheese acceptability and attributes from consumers at Oregon State University $(\mathrm{n}=111)$. scriptive analysis (Table 3 ). Cheese 3 was characterized by young flavors, whereas cheese 6 exhibited sulfur, nutty, and brothy flavors.

Several linear relationships among consumer and consumer/descriptive results were determined. Strong relationships were observed between "overall acceptance" and "overall flavor liking" ( $\mathrm{r}=0.99)$, "overall acceptance" and "overall texture liking" $(\mathrm{r}=0.93)$, "overall flavor liking" and "overall texture liking" $(\mathrm{r}=0.92)$, and "overall aged cheese intensity" and "overall cheddar cheese intensity" ( $\mathrm{r}=0.90)$ (Table 7). The consumer/ descriptive correlations (data not shown) showed minimal linear relationships. Negative relationships were observed between "whey" flavor and "overall aged cheese intensity" $(\mathrm{r}=-0.92)$ and "diacetyl" and "overall aged cheese intensity" $(\mathrm{r}=-0.94)$, suggesting that consumers do associate these flavors with young cheeses.

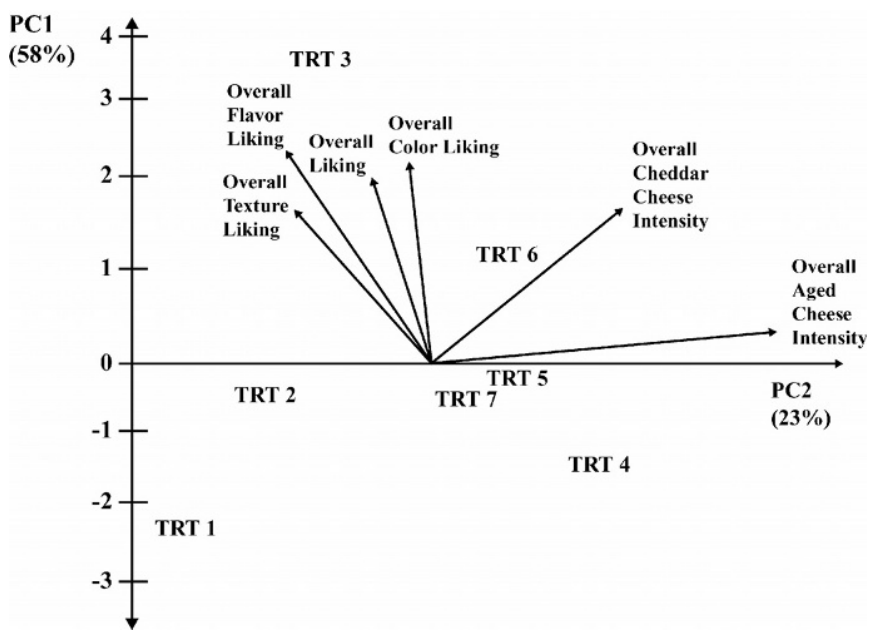

Figure 3. Internal preference map of perception of Cheddar cheese acceptability and attributes from consumers at North Carolina State University $(\mathrm{n}=101)$. 
Table 7. Correlations between consumer perceptions of cheese attributes. ${ }^{1}$

\begin{tabular}{|c|c|c|c|c|c|c|}
\hline & $\begin{array}{l}\text { Overall } \\
\text { acceptance }\end{array}$ & $\begin{array}{l}\text { Overall } \\
\text { color } \\
\text { liking }\end{array}$ & $\begin{array}{l}\text { Overall } \\
\text { flavor } \\
\text { liking }\end{array}$ & $\begin{array}{l}\text { Overall } \\
\text { texture } \\
\text { liking }\end{array}$ & $\begin{array}{l}\text { Overall } \\
\text { cheddar } \\
\text { cheese } \\
\text { intensity }\end{array}$ & $\begin{array}{l}\text { Overall } \\
\text { aged } \\
\text { cheese } \\
\text { intensity }\end{array}$ \\
\hline $\begin{array}{l}\text { Overall } \\
\text { acceptance } \\
\text { Overall color }\end{array}$ & 1.00 & 0.67 & 0.99 & 0.93 & 0.49 & 0.18 \\
\hline $\begin{array}{l}\text { liking } \\
\text { Overall flavor }\end{array}$ & & 1.00 & 0.62 & 0.73 & 0.69 & 0.38 \\
\hline $\begin{array}{l}\text { liking } \\
\text { Overall texture }\end{array}$ & & & 1.00 & 0.92 & 0.38 & 0.05 \\
\hline $\begin{array}{l}\text { liking } \\
\text { Overall cheddar }\end{array}$ & & & & 1.00 & 0.34 & 0.01 \\
\hline $\begin{array}{l}\text { cheese intensity } \\
\text { Overall aged }\end{array}$ & & & & & 1.00 & $\mathbf{0 . 9 0}$ \\
\hline
\end{tabular}

${ }^{1}$ Numbers in bold represent significant correlations $(P<0.01)$.

Scatterplot matrices were created to visually determine any nonlinear relationships existing between the consumer and descriptive/consumer attributes. No nonlinear relationships were observed (data not shown).

Because consumer results indicated that both young flavored and aged flavored Cheddar cheese were associated with high Cheddar cheese flavor intensity (Table 6) this suggests, not surprisingly, that the Cheddar cheese flavor concept varies among consumers. Cheese 1 , which was 1 mo old, was characterized by descriptive analysis as exhibiting young flavors (cooked/milky, whey, milk fat/lactone, diacetyl) and low sour and salty tastes. This cheese also received the lowest consumer scores for Cheddar cheese flavor intensity, which also suggests that while the Cheddar flavor concept may vary among consumers, it does not encompass Cheddar cheeses with extremely young and mild flavors.

Dacremont and Vickers (1994a) used the R-index method to evaluate the Cheddar cheese concept with 17 consumers and Cheddar and non-Cheddar cheeses. In general, consumers distinguished between Cheddar and non-Cheddar cheeses. Both aged and young Cheddar cheeses were used in their study also, although descriptive analysis was not conducted. Dacremont and Vickers (1994b) used analysis of variance and the Rindex method to evaluate the impact of individual volatile compounds on the Cheddar cheese aroma concept using 16 subjects who consumed Cheddar cheese regularly. Several Cheddar cheese extract mixtures were compared to several Cheddar and non-Cheddar cheeses. There were some relationships observed between the mixtures and the Cheddar cheese concept. Again, traditional descriptive analysis techniques were not used.

Subtle differences in consumer likes and dislikes may be missed by analysis of variance where overall means from a number of consumers are generated and com- pared. For this reason, external preference mapping was conducted to determine whether there were distinct segments of Cheddar cheese consumers within the populations polled. The GPA and cluster analysis revealed six distinct clusters or segments of consumers (Figures 4 and 5). Six distinct consumer segments is a large number considering there were only 7 cheeses in the study. However, the 7 cheeses were carefully screened and selected to exhibit distinct and diverse flavor profiles. Due to the diverse nature of the Cheddar cheeses, it is not surprising that 6 distinct consumer segments were identified. The overall preferred cheese for consumers in segment 1 was a cheese characterized primarily by young flavors (cooked/milky, diacetyl, milk fat/lactone, whey) but with low intensities of sulfur and brothy flavors (treatment 2). These individuals liked

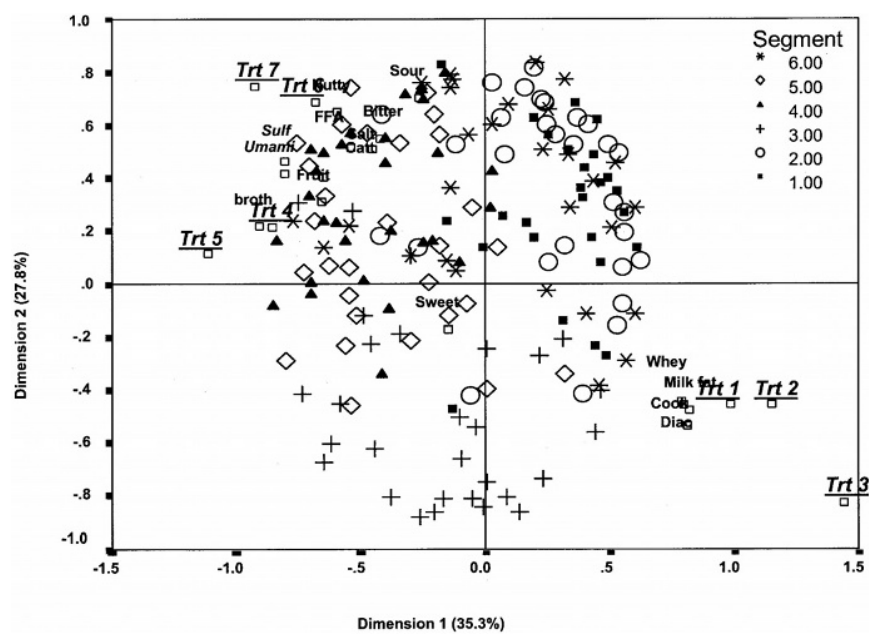

Figure 4. External preference map of combined consumer data (Oregon State University and North Carolina State University) with descriptive analysis results. Consumer segments are identified. 


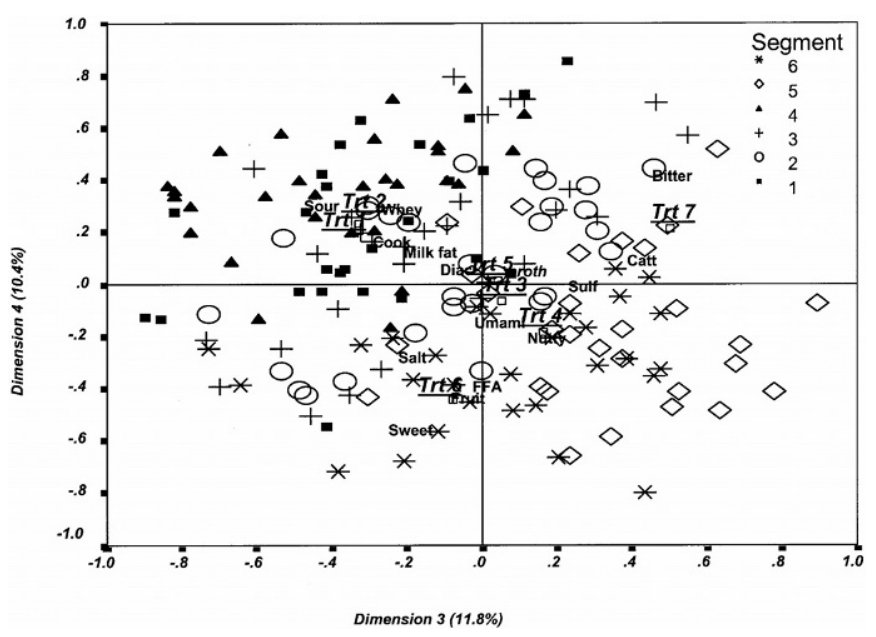

Figure 5. External preference map of combined consumer data (Oregon State University and North Carolina State University) with descriptive analysis results. Consumer segments are identified.

young flavored cheeses (cooked/milky, diacetyl, milk fat/lactone, whey) but also liked nutty flavor and bitter taste in aged cheeses. Consumers in segment 2 liked the same cheeses as consumers in segment 1 but exhibited equal liking intensities for those cheeses with no outstanding preference. Consumers in segment 3 preferred young and brothy flavored cheeses. Consumers in segment 4 liked all cheeses except cheese 1 , which was characterized by young flavors and a low intensity of sour taste. Consumers in segment 5 were characterized by their dislike of young-flavored cheeses. Consumers in segment 6 did not like brothy cheeses but did like other aged flavors including nutty and fruity flavors and sweet tastes.

There were differences in the numbers of consumers within each segment at the two locations (Figure 6). These differences were primarily located in segments 2 and 6 . Both of these segments were consumers that liked young and aged flavored cheeses, but they differed in specific likes/dislikes of cheese flavor. North Carolina consumers liked young and aged flavored cheeses, whereas Oregon consumers were more specific in terms of cheese flavor profiles they liked and preferred. For example, consumers in segment 2 liked cheeses 6 and 7 , both characterized by aged flavors, equally, whereas consumers in segment 6 preferred cheese 6 over cheese 7. According to their different preferences for cheese flavor, there were differences in how each segment scored acceptability of the Cheddar cheeses (Figure 7). These differences in preferences among the different consumer segments indicate that Cheddar cheeses with specific flavor profiles could be marketed to specific target market segments.

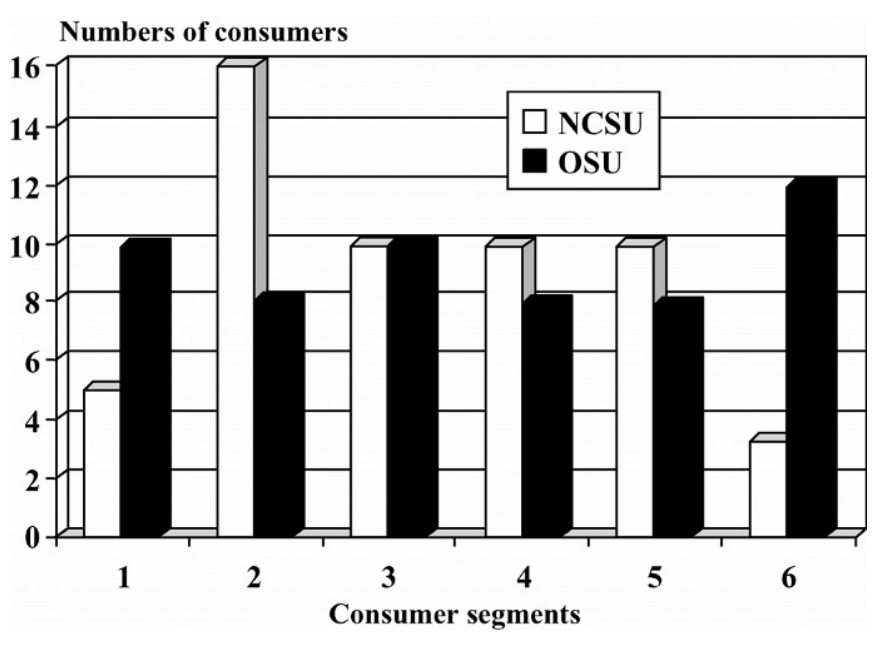

Figure 6. Consumer segment compositions at North Carolina State University $(\mathrm{n}=101)$ and Oregon State University $(\mathrm{n}=110)$.

Previous research has addressed cheese flavor and consumer testing methods, particularly Cheddar cheese. Piggott and Mowat (1991) evaluated Cheddar cheeses using descriptive analysis techniques, in which the cheeses varied in age/maturity. Descriptive analysis identified the differences in the cheeses according to age and showed that maturation (age) dictated cheese flavor strength, aftertaste, and mouthfeel characteristics (Piggott and Mowat, 1991). McEwan et al. (1989) used free-choice profiling and conventional methods to evaluate seven Cheddar cheese varieties. Their results indicated differences in matured cheese profiles, with results varying in flavor and texture profiles. Drake et al. (2001) confirmed these observations in their development of a referenced descriptive language for Cheddar cheese flavor.

Lawlor and Delahunty (2000) determined consumer preferences for 10 specialty Irish cheeses using external

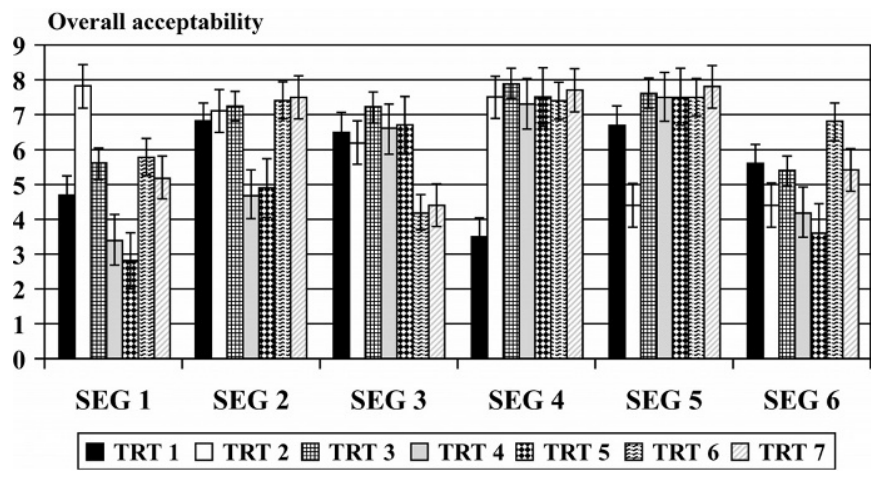

Figure 7. Overall acceptability scores for cheeses within different consumer segments. Acceptability was scored on a 9-point hedonic scale where 1 = dislike extremely and 9 = like extremely. 
preference mapping and cluster analysis. The results indicated diverse flavor differences among the different cheese varieties. Seven distinct consumer clusters were identified and related to their respective cheese sensory profiles. Wide consumer preferences would be expected among different types of cheeses. Murray and Delahunty (2000) conducted preference mapping with factory and farmstead Cheddar-type cheeses. Again, a wide variety was observed in descriptive flavor profiles of cheeses and in distinct consumer preference clusters. Consumer perception of "age" and "Cheddar flavor" were not evaluated. Our study indicates a wide variability in cheese preferences within one specific type of cheese: Cheddar cheese.

\section{CONCLUSIONS}

Descriptive analysis and consumer evaluation showed distinctive flavor profiles for all Cheddar cheeses and their relationship with acceptability. The concept of "Cheddar cheese" flavor varied widely among consumers, but consumers distinguished aged cheeses from young cheeses. These significant relationships illustrate that Cheddar cheese acceptance is related to maturity level and flavor characteristics and varies widely among consumers with specific segments preferring specific Cheddar flavor profiles.

\section{ACKNOWLEDGMENTS}

This study was funded in part by Dairy Management, Inc., the California Dairy Research Foundation, and the North Carolina Agriculture Experiment Station. Paper number 03-45 of the North Carolina Experiment Station, North Carolina State University. The use of trade names in the publication does not imply endorsement by these organizations nor criticism of ones not mentioned.

\section{REFERENCES}

Aston, J. W., and J. R. Dulley. 1982. Cheddar cheese flavour. Austr. J. Dairy Technol. 37:59-64.

Dacremont, C., and Z. Vickers. 1994a. Classification of cheeses according to their closeness to the Cheddar cheese concept. J. Sensory Stud. 9:237-246.

Dacremont, C., and Z. Vickers. 1994b. Concept matching technique for assessing importance of volatile compounds for Cheddar cheese aroma. J. Food Sci. 59:981-985.
Drake, M. A., S. C. McIngvale, P. D. Gerard, K. R. Cadwallader, and G. V. Civille. 2001. Development of a descriptive language for cheddar cheese. J. Food Sci. 66:1422-1427.

Drake, M. A., P. D. Gerard, S. Wright, K. R. Cadwallader, and G. V. Civille. 2002. Cross validation of a sensory language for Cheddar cheese. J. Sensory Stud. 17:215-229.

Drake, M. A., and G. V. Civille. 2003. Flavor lexicons. Comprehensive Rev. Food Sci. 2:33-40.

Drake, M. A., P. D. Gerard, J. P. Kleinhenz, and W. J. Harper. 2003. Application of an electronic nose to correlate with descriptive sensory analysis of Cheddar cheese. Lebensmittel-Wissenschaft und- Technologie. 36:13-20.

Fenelon, M. A., T. P. Guinee, C. Delahunty, J. Murray, and F. Crowe. 2000. Composition and sensory attributes of retail cheddar cheese with different fat contents. J. Food Comp. Anal. 13:13-26.

Green, M. L., and D. J. Manning. 1982. Development of texture and flavor in cheese and other fermented Products. J. Dairy Res. 49:737-748.

Guldfeldt, L. U., K. I. Sørensen, P. Strøman, H. Behrndt, D. Williams, and E. Johansen. 2001. Effect of starter cultures with a genetically modified peptidolytic or lytic system on Cheddar cheese ripening. Int. Dairy J. 11:373-382.

Guinard, J. X. 1998. Data collection and analysis methods for consumer testing. Pages 504-516 in Third International Food Science and Technology Conference. Davis, CA.

Hough, G., and R. Sánchez. 1998. Descriptive analysis and external preference mapping of powdered chocolate milk. Food Qual. Pref. 9:197-204

Lawlor, J. B., and C. M. Delahunty. 2000. The sensory profile and consumer preference for ten specialty cheeses. Int. Dairy Technol. J. 53:28-36.

McEwan, J. A., J. D. Moore, and J. S. Colwill. 1989. The sensory characteristics of Cheddar cheese and their relationship with acceptability. J. Soc. Dairy Technol. 42:112-117.

McEwan, J. A. 1996. Preference mapping for product optimization. Pages 71-80 in Multivariate Analysis of Data in Sensory Science. T. Naes and E. Risvik, eds. Elsevier, Amsterdam, The Netherlands.

Muir, D. D., J. M. Banks, and E. A. Hunter. 1997. A comparison of the flavour and texture of cheddar cheese of factory or Farmhouse origin. Int. Dairy J. 7:479-485.

Murray, J. M., and C. M. Delahunty. 2000. Consumer preference for Irish farmhouse and factory cheeses. Ir. J. Food. Agric. Res. 39:433-449.

Murray, J. M., and C. M. Delahunty. 2000. Mapping consumer preference for the sensory and packaging attributes for Cheddar cheese. Food Qual. Pref. 11:419-435.

Pagliarini, E., E. Monteleone, and I. Wakeling. 1997. Sensory profile description of mozzarella cheese and its relationship with consumer preference. J. Sensory Stud. 12: 285-301.

Piggott, J. R., and R. G. Mowat. 1991. Sensory aspects of maturation of cheddar cheese by descriptive analysis. J. Sensory Stud. 6:49-62.

Richardson-Harman, N. J., R. Stevens, S. Walker, J. Gamble, M. Miller, M. Wong, and A. McPherson. 2000. Mapping consumer perceptions of creaminess and liking for liquid dairy products. Food Qual. Pref. 11:239-246.

Schlich, P. 1995. Preference mapping: relating consumer preferences to sensory or instrumental measurements. Pages 231-245 in Bioflavour '95. Analysis/Precursor Studies/Biotechnology. P. Etivant \& P. Schreier, eds. INRA Editions, Versailles, France.

Urbach, G. 1995. Contribution of lactic acid bacteria to flavor compound formation in dairy products. Int. Dairy J. 5:877-903.

Yackinous, C., C. Wee, and J. X. Guinard. 1999. Internal preference mapping of hedonic ratings for Ranch salad dressings varying in fat and garlic flavor. Food Qual. Pref. 10:401-409. 